\title{
FENOMENA EKSPLOITASI LINGKUNGAN DALAM CERPEN KORAN MINGGU INDONESIA PENDEKATAN EKOKRITIK
}

\author{
Juanda \\ Universitas Negeri Makassar \\ juanda@unm.ac.id
}

\begin{abstract}
ABSTRAK
Kerusakan lingkungan di bumi berada pada tingkat yang kritis. Perubahan iklim, bencana, polusi, dan perburuan hewan terus terjadi tanpa disadari bahwa manusia sebagai bagian daripada kehidupan mereka. Tujuan dalam penelitian ini, pertama, mengeksplorasi bentuk pengimajian pengarang cerpen Indonesia yang bertemakan lingkungan. Kedua, menganalisis unsur ekokritik yang direfleksikan pengarang melalui cerpen Koran Minggu Indonesia. Penelitian ini menggunakan metode deskriptif kualitatif.pendekatanyang digunakan adalah pendekatan ekokritik Garrard. Sumber data terdiri atas tiga cerpen, yakni, "Di Seine Meratapi Citarum", Pergi ke Bukit, dan Daun, Pohon dan Petrichor. Analisis data dimulai dengan menandai kata, frasa, klausa, dan kalimat yang memiliki fokus eksploitasilingkungan. Hasil penelitian menunjukkan dalam cerpen Koran Mingguan Indonesia, pengarang merefleksikan fenomena lingkungan yang meliputi pencemaran air, perusakan hutan, bencana alam berupa longsor di bukit tambang emas. Eksploitasi alam yang membawa korban jiwa. Fenomena lingkungan yang terdapat dalam cerpen tersebut berfokus pada polusi, hutan belantara, bencana alam, pemukiman, hewan, dan bumi.
\end{abstract}

Kata kunci: ekokritik, cerpen, eksploitasi lingkungan.

\section{EXPLOITATIONPHENOMENA IN THE ENVIRONMENTAL IN THE SHORT STORIES WEEKLY NEWSPAPER IN INDONESIA WITH ECOCRITIC APPROACH}

\begin{abstract}
Environmental damage on earth is at a critical level. Climate change, disaster, pollution, and animal hunting continue to occur without realizing that humans are part of their lives. The purpose of this research, first, is to explore the form of imagination of

AKSIS Jurnal Pendidikan Bahasa dan Sastra Indonesia

Volume 2 Nomor 2, Desember 2018 e-ISSN: 2580-9040

e-Journal: http://doi.org/10.21009/AKSIS
\end{abstract}


Indonesian story writer with the theme of environment. Second, to analyze the ecocritical element that is reflected by the author through short story weekly newspaper in Indonesia. This study used descriptive qualitative method. The approach this research used is Garrard's ecocritical approach. The data source consists of three short stories, namely, "In the Seine Lamenting of Citarum Rivers", Go to the Hill, and Leaves, Trees and Petrichor. Data analysis begins by marking words, phrases, clauses, and sentences that have the focus of environmental exploitation. The results showed in short story weekly newspaper, Indonesia the author reflects the environmental phenomenon that includes water pollution, forest destruction, natural disaster in the form of landscapes in the hills of gold mines. Exploitation of nature that brings casualties. Environmental phenomena contained in the short story focuses on pollution, wilderness, natural disasters, settlements, animals, and the earth.

Keywords: ecocritism, short story, environmental exploitation

\section{PENDAHULUAN}

Sejak zaman empirisme modern, manusia seolah mencapai batas kejayaannya dengan pencapaian ilmu-ilmu positif. Perkembangan kebudayaan dalam berbagai aspek pun berkembang pesat, mulai industri mesin, persenjataan, hingga kebudayaan secara luas. Kita tidakdapat memungkiri bahwa segala sesuatu dalam pencapaian perabadan manusia modern merupakan bagian dari hasil eksploitasi alam. Manusia memenuhi kebutuhannya dengan pembalakan hutan, penambangan, perburuan binatang, hingga penggunaan mesin yang mengakibatkan peningkatan polusi dan pemanasan suhu bumi secara global, serta berbagai bencana alam timbul. Issu-issu mengenai lingkungan seringkali diangkat penulis dalam karya sastra (Maharam, 2015). Seorang penulis karya sastra memiliki keunggulan dalam menggunakan imajinasinya (Dewi, 2016). Sebuah karya sastra terkadang mengungkapkan realitas kehidupan nyata.

Fenomena lingkungan merupakan permasalahan global. Semua disiplin ilmu telah mengkaji tata cara penanganan lingkungan di dunia. Sastra telah turut andil dalam mengkaji persoalan lingkungan seperti dalam gendre sastra novel, cerpen, puisi, drama ,

AKSIS Jurnal Pendidikan Bahasa dan Sastra Indonesia

Volume 2 Nomor 2, Desember 2018 e-ISSN: 2580-9040

e-Journal: http://doi.org/10.21009/AKSIS 
dan film.Lingkungan telah disoroti dalam berbagai karya sastra dengan media cerpen yang dimuat dalam Koran Mingguan. Media cerpen telah dimuat di media Indonesia antara lain, Republika, Tribun Jabar, Banjarmasin Post, dan lain-lain. Penelitian mengenai cerpen ditinjau dari segi ekokritik telah dilakukan oleh berbagai ahli antara lain:(Trisnawati, 2014); (Mamat, 2015); (Tina, 2016); (Wiyatmi, 2016); (Junaedi, 2017); Juanda (2018). Penelitian ini menyoroti, polusi air, khususnya sungai- sungai diperkotaan, bencana alam seperti longsor dan pembalakan hutan.Fenomena tersebutyang terjadi di wilayah Indonesia yang diimajikan oleh pengarang melalui cerpen.

Berdasarkan beberapa penelitian di atas semuanya mengkaji cerpen dengan pendekatan ekokritik namun hanya bagian demi bagian dalam keenam ranah ekokritik. Misalnya, banjir, polusi, dan bencana alam. Belum ada yang secara totalitas mengkaji keenam poin dalam ekokritik yaitu, polusi, hutan belantara, bencana alam, pemukiman, hewan, bumi. Oleh karena itu, penelitian ini akan mengkaji cerpen dengan tema lingkungan secara tuntas. Cerpen dalam cerpen Koran Minggu Indonesiadengan pendekatan ekokritik Garrard.

Masalah dalam penelitian ini sebagai berikut. Pertama, bagaimanakah bentuk pengimajian pengarang cerpen Indonesia yang bertemakan lingkungan. Kedua, unsur ekokritik apa sajakah yang direfleksikan pengarang dalam cerpen berdasarkan pendekatan ekokritik Garrad seperti: polusi, hutan belantara, bencana alam, pemukiman, hewan, bumi. Adapun tujuan dalam penelitian ini sebagai berikut: Pertama, mengeksplorasi bentuk pengimajian pengarang cerpen Indonesia yang bertemakan lingkungan. Kedua, menganalisis unsur ekokritik yang direfleksikan pengarang melalui cerpen Koran Minggu Indonesia. Penelitian ini memiliki manfaat, 
yaitu: secara teoretis penelitian ini diharapkan dapat menambah perbendaharaan penelitian di bidang sastra khususnya karya sastra di bidang cerpen dengan menggunakan pendekatan ekokritik Garrard. Secara praksis penelitian ini diharapkan memberikan pemahaman dan kesadaran kepada pembaca karya sastra pentingnya menjaga lingkungan.

Ekokrotisisme adalah ilmu yang interdisipliner sebagaimana yang dijelaskan Coupe (2006) "Ecocritism is the study of explicit environmental text by way of any scholarly approach or, conversely, the scrutiny of ecological implications and humannature relationship in any literary text, even texts that seem..., oblivious of the nonhuman world.". Selanjutnya, (Harsono, 2008) mengemukakan bahwa teori ekokrokritisme bersifat interdisipliner. Pada satu sisi ekokritik menggunakan teori ekologi dan disisi lain menggunakan teori sastra. Oleh karena itu, teori ekokritik merupakan pendidikan tentang pemahaman lingkungan melalui sastra.

Selanjutnya Glotfelty dan Harol Fromm (1996) mengetengahkan gagasan tentang ecocriticism atau ekokritik dengan mengaplikasikan konsep ekologi ke dalam karya sastra.Pendekatan ini dilakukan dengan menjadikan alam sebagai pusat kajiannya.Menurut Syahrul (Juliasih, 2012), ekokritik meliputi studi tentang hubungan antara manusia dan nonmanusia, sejarah manusia, dan budaya yang berkaitan dengan analisis kritis tentang manusia dan lingkungannya.Pandangan yang lebih luas tentang ekokrtik (Garrard, 2004) bahwa ekokritik bisa membantu menentukan, mengeksplorasi, dan bahkan menyelasaikan permasalahan ekologi dalam pengertian yang lebih luas.Mengingat bahwa sastra tumbuh dari lingkungan masyarakat dan lingkungan alam (ekologi), dalam fungsinya sebagai media representasi, pandangan, refleksi atas kenyataan hidup sastra memiliki peranan penting dalam perubahan tata nilai 
kemasyarakatan, tata nilai hidup bersama dan tata nilai kearifan lokal.Ekokritisisme secara sederhana dapat didefinisikan sebagai kajian tentang hubunan antara sastra dan lingkungan hidup (Glotfelty, 1996).

Buell (1996) menyebutkan bahwa ekokritik diperkenalkan pada pertengahan 1990-an dengan terbitnya buku The Ecocritism Reader. Ekokritik adalah “....the study of the relationship between literature and the physical environment. Ekokritik menurut Wiyatmi (Love, 2003: 2), kajian yang menghubungkan karya sastra dengan lingkunganfisik, pertumbuhan populasi, hilangnya hutan liar dan belantara, kepunahan spesies hewan dengan cepat, serta peningkatan polusi dan kontaminasi udara, air, dan tanah di bumi.

Shakespeare melihat hubungan implisit dan eksplisit dalam teks-teks sastra antara manusia dan hewan (Estok, 2011). Faktanya, implisit dalam analisis teks ini adalah arus kuat daribudaya pribumisasi yang membawa identitas yang berpusat di Taiwan yang memuliakan perpaduan budaya yang khas dan keindahan gunung dan sungai. Masyarakat adat Austronesia sebagai Taiwan asli dalam citra nasionalistik ini, dan pemandangan alam dengan flora dan faunanya membentuk warisan kolektif serta nasionalisme Taiwan sebagai budaya multicultural. Pengarang sastra Taiwan mengembangkan karya sastra dan artistik yang sadar lingkungan. Gaya khusus "vernakular kosmopolitan" ditemukan untuk menghidupkan eksplorasi dan diskusi intelektual ini, karena penulis yang berakar lokal sedang memperhatikan tren global. Hasilnya adalah campuran kreatif, masyarakat pribumi Taiwan memainkan peran penting sejak gaya hidup dan mitos pra-kolonial mereka memberikan inspirasi yang taat untuk bagaimana Taiwan dapat mendamaikan kontradiksi antara kapitalisme industri secara keberlanjutan.

AKSIS Jurnal Pendidikan Bahasa dan Sastra Indonesia

Volume 2 Nomor 2, Desember 2018 e-ISSN: 2580-9040

e-Journal: http://doi.org/10.21009/AKSIS 
Taiwan telah menyaksikan gelombang protes lingkungan selama dekade terakhir. Proyek di taman sains dan resor wisata, yang pernah dilihat sebagai stimulus yang sangat dibutuhkan dalam situasi ekonomi yang lesu, berganti menghadapi resistensi lokal. Pada tahun 2011, pemerintah terpaksa membatalkan proyek besar petrokimia dan pembangunan pembangkit listrik tenaga nuklir dipetieskan pada tahun 2014. Dengan Munculnya pemerintahan Partai Progresif yang Demokratis pada tahun 2016, sebuah program energi terbarukan yang ambisius sedang berlangsung; Taiwan diperkirakan akan benar-benar bebas energi nuklir tahun 2017, negara Asia pertama yang memulai program pro-lingkungan. Negara Asia pertama yang memulai kursus prolingkungan bertentangandengan latar belakang yang disebutkan di atas. Secara sepintas lalu ia mengambil langkah-langkah untukpenyelamatan lingkungan. Pengarang sastra seperti WangChia-hsiang, Wusheng, andWuMing-yi (Chia and Scot Slovic, 2016).Menulis Lingkungan dalam Kesusastraan Amerika Abad Kesembilan Belas dimulai dengan komentar yang mengungkap Henry David Thoreau, yang tulisan menjadi batu ujian bagi kritikus lingkungan Amerika. Ekspresi adalah tindakan dari seluruh manusia (Purwahida, 2017). Seorang penulisadalah pencipta semua alam sebagai perpaduan tubuh dan pikiran (Rudd, 2017). Flannery tampaknya menunjukkan kecenderungan dalam sastra lingkungan. 'New York Time' karya Derek Mahon,Penyair kelahiran Belfast, misalnya, untuk menciptakan karya-karya yang menarik diri dari individualistik dan menuju mode global tempat tinggal di dunia 'truk sampah' dan 'tongkang pengungsian' dengan limbah (Gerald, 2017).

Ekokritik telah dikenal di India pada tahun 1980 yang diperkenalkan oleh Nirmal Selvamoni, mahsisa di Fakultas Keristen Madras, Chennai. Ekokritik telah berkembang di India antara tahun 1980 hingga 2004 dan dikenal secara internasional. 
Pusat kajiannya pada puisi moder Tamil.Puisi ini mengekspresikan kerusakan alam dan kehidupan manusia yang berkaiatan budaya dan alam seperti sungai (Murugesan, 2016).

Mishra (2017) mengkaji beberapa isu ekokritis di India yang diwakili dalam novel alam yang agung "Aranyak, Of the Forest" karya salah seorang novelis Benggali yang bernama Bandyopadhyay. Pada awal novelnya menceritakan penduduk kota dengan penebangan hutan dan sikap mereka terhadap alam. Akhir novel ini menimbulkan kesadaran lingkungan.Interaksi manusia dengan hewan perlu dijaga.Novel Kontemporer Postkolonial yang menggambarkan pertemuan antara manusia dan hewan (Bartosch, 2013). Sementara Novel karya Ursula K.Le Guin di Vietnambertemakan malapetaka terhadap sikap antroposentris manusia terhadap alam di masa depan bilamana manusia mengeksplorasi alam secara tidak seimbang (Sureci, 2017).

Teori ekokritik mengolaborasikan antara sastra dan ekologi.Sastra berhubungan dengan hal yang bersifat imajinatif, namun sastra terkadang membahas realitas. Ekologi membahas mengenai atau issu-issu lingkungan, social, politik, maupun budaya. Sastra Penelitian ini menghubungkan antara karya sastra, lingkungan (ekologi), serta hubungan timbal balik antara manusia dengan alam semesta, dengan menggunakanteori yangdijelaskan oleh Gerard dengan data penelitian cerpen dalam media Koran Mingguan Indonesia.

\section{METODE PENELITIAN}

Penelitian ini menggunakan metode deskriptif kualitatif. Metode yang digunakanbertujuan untuk memecahkan atau menjawab permasalahan yang sedang 
dihadapi pada situasi sekarang atau masalah yang aktual dengan jalan mengumpulkan, menyusun, mengklasifikasikan, menganalisis, dan interpretasi.Analisis cerpen diawali dengan membaca, mencatat, analisis, lalu mendeskripsikan.Data dalam penelitian ini bersumber dari tiga cerpen dari Koran Mingguan Indonesia, yaitu, "Di Seine Meratapi Citarum”, karya Romli H.M.Tribun Jabar, 10 Desember 2017,“Pergi ke Bukit” Karya Tjak Parlan, Republika, 4 Juni 2017 ; “Cerita Daun Pohon dan Petrichor” karya Faritz Al Faisal, Banjarmasin Post, 15 April 2018. Data dianalisis dengan pendekatan ekokritik Garrardyang memfokuskan persoalan lingkungan pada polusi, hutan belantara, bencana alam, pemukiman, hewan, bumi, lalu diberikan interpretasi secara totalitas.

\section{HASIL DAN PEMBAHASAN}

\section{Bentuk Pengimajian Pengarang Cerpen Indonesia.}

Usep Romli H.M. adalah sastrawan Sunda yang lahir di Limbangan. Garut. 16 April 1949. Usep menulis, terutama dalam bahasa Sunda, sejak masih duduk di SPG.Sajak dan cerita pendeknya dimuat di sejumlah media. Ia pernah menerima berbagai penghargaan, termasuk Hadiah Sastra LBSS dan Hadiah Sastra Rancage. Pengarang ini merefleksikan fenomena lingkungan dengan membandingkan Kota Bandung di Indonesia dengan Kota Paris di Perancis.Dia mengimajikan fenomena lingkungan dalam bentuk sungai. Sungai Citarum merupakan sungai yang membelah Kota Bandung sudah sangat tercemar, padahal pada tahun 1920-an sungai ini merupakan ikon sungai Seine di Paris yang kita kenal pada jaman sekarang sebagai objek pariwisata yang bebas pencemaran air.

Faris Al Faisal, lahir dan domisili di Indramayu.Karya yang terbit novella Bunga Narsis (2017). Kumpulan Puisi Bunga Kata (2017), Kumpulan Cerpen Bunga Rampai 
Senja di Taman Tjimanoek (2017), dan buku Mengenal Rancang Bangun Rumah Adat di Indonesia (2017), di beberapa media massa. Faisal mengimajikan fenomena lingkungan dengan merefleksikan pohon yang dapat berbicara.Dalam pembicaraan ini pohon memiliki peran besar dalam kehidupan.Pohon dapat bertahan dari rendaman air pada musim hujan dan dapat bertahan dari kekeringan pada musim kemarau.Daun pohon yang berguguran menjadi petrichor atau dapat menjadi pupuk organik untuk keberlanjutan kehidupan pohon itu sendiri dan tanaman lainnya di sekitarnya.

Tjak S. Parlan lahir di Banyuwangi, 10 November 1975. Cerpen dan puisinya sudah disiarkan di sejumlah media. Mukim di Mataram, Nusa Tenggara Baratmengimajikan fenomena lingkungan dalm bentuk bencana tanah longsor di perbkitan akibat ulah manusia yang melakukan penmbangan liar. Bukit yang dulunya hutan belantra dieksploitasi oleh penduduk di sekitarnya.Perbukitan akhirnya longsor dan menimbun para petambang yang sedang beraktivitas dan menimbulkan korban jiwa.

Cerpen "Di Seine Meratapi Citarum" bercerita tentang rombongan turis asal Bandung yang tiba di Paris. Persoalan yang diangkat dalam cerpen tesebut, yakni polusi atau pencemaran air sungai dan sungai tersebut berada di kota.Udara di sekitar sungai mengalami polusi akibat pembuangan sampah dan limbah rumah tangga. Pengarang mengimajikan perbandingan ditempat wisata yang ada di Kota Paris dengan Kota Bandung, Sungai Cikapundung dan Citarum yang kini menjadi septic tank terpanjang di dunia. Kemudian, cerpen berjudul "Cerita Daun, Pohon dan Petrichor" bercerita tentang pohon yang berbicara dengan tokoh Aku dalam cerpen. Dalam cerpen mengisahkan tentang pentingnya merawat pohon demi kelestarian lingkungan.Pada cerpen "Pergi ke Bukit" bercerita tentang peristiwa tanah longsor di bukit tambang emas. Tokoh ibu 
Kayah dalam cerpen kehilangan anaknyayang meninggal akibat tertimbun reruntuhan tanah di atas bukit pertambangan.

\section{Unsur Ekokritik Cerpen Koran Minggu Indonesia}

Berikut unsur ekokritik yang ditemukan pada setiap cerpen dengan menggunakan teori Garard yang mencakup enam persoalan lingkungan. Pengarang mengimajikan dalam bentuk cerpen mengenai persoalan pencemaran air yang menyebabkan air sungai kotor dan berbau, bencana alam seperti tanah longsor akibat penambangan liar, pentingnya merawat pohon, dan pemeliharaan hewan. Persoalan lingkungan yang ditemukan dalam cerpen sebagai berikut:

\section{Polusi}

Pada cerpen "Di Seine Meratapi Citarum"mengisahkan tentang Rombongan turis asal Bandung yang tiba di Paris.Para wisatawantersebut terpukau melihat keindahan wisata Kota Paris yang begitu bersihserta penduduk menjaga kelestasrian lingkungan mereka.Rombongan wisatawan tersebut teringat wisata kota asalmerekadi Cikapundum dan CitarumKota Bandung. Penulis merefleksikan Sungai Citarum sebagai kota yang telah membangkai. Makna bangkai dalam konteks cerita diartikan sebagai sungai yang kotor, bau, air tercemar,bersampah dan banyak limbah rumah tangga. Selain itu, tatanan kota kacau balau, dan dipadati pedagang. Fenomena pencemaran air sungai ini dapat dilihat pada kutipanpercakapan tokoh dalam cerpen di bawah ini.

“Ja, als Parisj...!" (Ya, mirip Paris). "We noemen het Parisj van Java!” (Paris asal Jawa). "Ja, Paris van Java!" (Oh, Paris di Jawa)"Persis Seine!" Sinyohmelihat ke Cikapundung. "Seine mengalir di tengah kota Paris. Rive Droite, bagian kanan, dan Rive Gauche, bagian kiri," jawab.Kata temanku pada tulisannya:"Percakapan Sinyoh 
dan Nonih itu masih berlangsung. Sebagai pembicaraan orang banyak. Padahal situasi itu tahun 1920-an. Bandung tak bisa memperoleh julukan Paris van Java pada zaman sekarang karena penuh sampah dan semrawut penataan kotanya."(Romli, 2017).

Berdasarkan kutipan di atas ternyata Bandung sangat indah dan bebas polusi pada tahun 1920-an. Sungai Citarum airnya sama dengan Sungai di Paris pada saat sekarang. Bilamana penduduk tidak membuang sampah sembarangan dan aktif memelihara kebersihan sungai tentu sungai kita akan menyamai Paris. Sekarang Sungai yang ada di kota-kota besar di Indonesia airnya sudah berubah menjadi air got sebab para penduduk menjadikan sungai sebagai tempat pembuangan sampah dan kotoran. Contoh kutipan di bawah ini.

"Sekarang Bandung tidak layak lagi menyandang gelar Paris van Java. Sebab sudah penuh sampah, tata kota kacau balau, trotoar padat pedagang. Bangunan berlatar historis banyak diruntuhkan dan menjadi are bisnis. Berbeda dengan Paris yang tetap menjaga lingkungan dan gedung bersejarahnya. Sungai-sungainya sehat, bermanfaat dan terawat. Bukan tempat pembuangan sampah seperti Cikapundung dan Citarum(Romli, 2017).

Di Paris, Perancis, serta negara-negara Eropa lainnya, orang yang membuang sampah atau kotoran ke sungai, akan dikucilkan oleh warga sekitar. Hal ini menjadikan para warga menjaga limbah rumah tangga mereka agar tidak mencemari air sungai. Bilamana ada warga yang mencemari atau membuang limbah ke sungai mereka akan diajukan ke pengadilan. Selain itu, warga yang tidak memperhatikan kebersihan sungai akan mendapat hukuman denda ribuan euro dan penjara sebagai hukuman yang setimpal. Oleh kaena itu, pemerintah mewajibkan penghuni setiap rumah yang berada di depan sungai memiliki pembuangan kotoran agar kotoran dan limbah tidak mencemari air sungai dan kotoran tersebut memudahkan petugas kebersihan mengangkut ketempat pengolahan limbah. Berikut percakapan tokoh di bawah ini.

AKSIS Jurnal Pendidikan Bahasa dan Sastra Indonesia

Volume 2 Nomor 2, Desember 2018 e-ISSN: 2580-9040

e-Journal: http://doi.org/10.21009/AKSIS 
"Di Paris, di Prancis, serta negara-negara Eropa lain, orang yang membuang sampah atau kotoran ke sungai akan didenda ribuan euro serta dihukum, dipenjara, dikucilkan oleh tetangga dan warga sekitar. Mereka yang diajukan ke pengadilan akan mendapat hukuman setimpal. Tiap rumah wajib memiliki sarana pembuangan kotoran.Dan pada hari tertentu kotoran tersebut dibawah ke tempat pengolahan limbah" (Romli, 2017).

\section{Hutan}

Cerpen "Cerita Daun, Pohon dan Petrichor" yang selanjutnya disingkat CDPP. Mengisahkan sebatang pohonraksasa yang bisa berbicara dengantokoh lelaki muda dalam cerpen. Pohon tersebut telah berumur atau lebih tua dari umur lelaki tersebut. Penulis mengimajikannya dengan menggunakan bentuk pengungkapan pohon yang dapat berbicara seperti manusia. Hal ini menyiratkan kepada pembaca betapa perlunya merawat tumbuhan, seakan pohon tua tersebut membutuhkan perhatian manusia agar dirawat dengan baik. Selain itu, pohon memang memberikan manfaat bagi ekosistemkarena pepohonan berfungsi menjagakeseimbangan alam. Keseimbangan alam perlu dijaga agar tidak terjadi banjir, global warming, angin ribut, dan prahara lainnya. Fenomena alam ini terdapatdalam percakapan berikut ini.

Pohon itu menandakan umurnya lebih lama daripada umur manusia.Dahan dan rantingnya kembali bergoyang. Daunnya berguguran di sekitar batang pokoknya dan akarnya.(Faisal, 2018).

Barangkali, kaumku saja yang tidak beranjak dari tempat duduknyaditimpa angin ribut dan prahara, salju, banjir, panas, dan hujan. Biarpun kering kerontang, pada musim kemarau, tenggelam lautan, terendam air, pohon tetap kokoh.”(Faisal, 2018)

Tentu saja.Saya sebagai keturunan ke sembilan pohon itu. Manusia harusnya lebih paham daripada pohon, karena berakal."(Faisal, 2018) 
Pohon memberikan banyak manfaat bagi kehidupan. Bahkan, setelah daunnya jatuh berguguran dapat bermanfaat bagi tanaman lain sebagai pupuk kompos.Persoalan ini dilukiskan oleh pengarang seperti dalam kutipan berikut.

Beberapa hari lagi, daun-daun terurai menjadi humus.Hal ini dapat menyuburkan kembali tanah yang tandus. Menakjubkan! Seandainya manusia pun seperti pohon, apa yang yang telah dikeluarkannya sebagai sisa masih bisa dimanfaatkan" (Faisal, 2018).

Pohon Tua tersebut berbicara seperti manusia.Pohot tua tersebut seakan membutuhkan perhatian manusia agar dirawat dengan baik, sehingga dapat tumbuh sehat dan subur.Hal ini merupakan bentuk imaji yang digunakan oleh penarang bahwa tumbuhan juga perlu perlakuan seperti manusia.Kutipan cerpen di bawah ini memperlihatkan hal tersebut.

"Semisal ilmu filsafat, pohon tidak hanya dapat berbicara, ia mampu serta peka merasakan sakit atau menjerit. Jadi, pohon yang dirawat dengan kasih sayang dan diajak bercakap-cakap, akan hidup lebih sehat serta subur (Parlan, 2017).

"Sejak di bukit ditemukan batu-batu yang, katanya, dapat didulang jadi emas, kebun telah tiada penggarapnya. Semakin banyak laki-laki ke bukit, meskipun adakalanya mereka tidak kembali lagi untuk selamanya“(Parlan, 2017).

\section{Bencana Alam}

Cerpen yang berjudul "Pergi ke Bukit" di singkat (PB).Cerita mengenai bencana tanah longsor yang terjadi bukit pertambangan emas.Para Penduduk desa maupun dari tempat lain berlomba-lomba melubangi bukit untuk mencari emas. Seperti pada kutipan berikut:

Sejak perbukitan di sekitar perkampungan mereka diserbu oleh orang-orang yang berasal dari berbagai daerah, warga di kampungnya pun berduyun-duyun ke sana. Orang-orang melubangi bukit itu mencari emas. Sementara, yang lainnya, yang belum beruntung, tak ada pilihan lain selain cepat-cepat kembali ke bukit dengan harapan bahwa berikutnya merekalah yang akan mendulang emas(Parlan, 2017). 
Selain itu, dampak nyata kerusakan bukit berujung pada kematian tokoh Dali.Ia meninggal tertimbun tanah longsor saat menggali lubang. Kutipan cerpen sebagai berikut.

"Kami telah menempuh berbagai cara menyelamatkannya. Tetapi takdir anakmu sampai di sini," ujar seseorang."Bersama dua penambang lainnya, Dali tertimbun tanah longsor waktu menggali lubang."(Parlan, 2017).

\section{Pemukiman}

Pemukiman merupakan persoalan yang melanda kota-kota yang ada di Indonesia.Kota tidak memiliki ruang hijau.Sungai-sungai yang membelah wilayah perkotaan airnya tidak layak digunakan oleh penduduk sekitrnya untuk keperluan hidup sehari-hari.Umumnya perumahan di bantaran sungai menjadikan sungai sebagai tempat pembuangan sampah dan kotoran.Contoh kutipan cerpen di bawah ini.

"Kota Bandung sekarang tak layak dijuluki Paris van Javakarena penataan kotanya semrawut.Bangunan yang memiliki nilai sejarah telah diruntuhkan dan diganti dengan kawasan bisnis.Sementara Kota Paris di Eropa tetap menjaga gedung bersejarahnya dan lingkungan,. Sungai-sungainya dipelihara dari polusi air.(Romli, 2017).

Penataan perkotaan di luar negeri, khususnya Paris sangat bagus dengan menjadikan sungai di perkotaan sebagi objek pariwisata.Contoh kutipan dibawah ini.

"Setiap rumah di piggir sungai, bagian depan rumahnya harus menghadap ke sungai. Tiap rumah wajib memiliki sarana pembuangan kotoran yang pada hari tertentu kotoran tersebut diangkut ke tempat pengolahan limbah.”(Romli, 2017). 


\section{Binatang}

Kehidupan binatang terganggu oleh eksploitasi alam yang dilakukan manusia. Banyak jenis burung yang telah hilang dari pandangan mata, telah punah akibat hutan telah diekploitasi oleh manusia menjadi pemukiman dan menjadi pertambangan. Contoh kutipan di bawah ini.

"Seperti burung-burung di atas pepohonan sepanjang bantaran Sungai Cikapundung, yang mengaliri pertengahan kota Bandung" ( Romli, 2017).

Kehidupan manusia tidak pernah lepas dari keberadaan binatang.Binatang dapat dijadikan sebagai alat transportasi dan sebagai alat untk membantu mngolah sawah di pedesaan.Selain itu binatang ternak seperti sapi merupakan sumber protein yang menjadikan keberlangsungan kehidupan manusia di dunia ini.Contoh kutipan cerpen di bawah ini.

"Semenjak Burhan, suaminya, tak pernah kembali lima tahun lalu, ia menggantungkan harapannya kepada Dali. Kehilangan salah satu anggota keluarga merupakan bencara besar. Lima tahun lalu suaminya menjual lima ekor karbau yang sering digunakan membajak sawah untuk ongkos ke Malaysia" (Parlan, 2017).

"Burhan memiliki dua ekor kerbau yang dipekerjakan sehari-hari.Dulu, orangorang di kampung selalu menggaji Burhan membajak sawah atau ladang menjelang waktu musim tanam tiba (Parlan, 2017).

"Menggembalakan sapi atau kerbau piaraan di kebun mereka yang terbengkalai.Sementara itu, kaum wanita mengerjakan berbagai kegiatan seperti: memasak (Parlan, 2017)

\section{Bumi}

Kehidupan di permukaan bumi pada saat sekarang telah terjadi berbagai hal yang anomali.Pergantian cuaca terjadi secara tiba-tiba, kemarau yang berkepanjangan, 
musim hujan yang terus-menerus mengakibatkan bencana banjir, longsor.Bumi telah mengalami pemanasan global.Contoh kutipan di bawah ini.

"Sekonyong-konyong datang angin kencang, sinar surya meredup, awan hitam menggulung angkasa lalu langit riuh rendah dengan cahaya berkilat-kilat dan bunyi guruh bergemuruh seperti sengaja dikirimkan malaikat Mikail ke tempatku sementara bercakap-cakapsama pohon ini. Berasal dari barat, butir-butir air langit berjatuhan didedaunan pepohonan. Lembut, rapat tiada terbendung derasnya. Langit bak meludah dan hujan pun tumpah.Angkasa menjadihingar-bingar.'(Faisal, 2018).

Usep Romli H.M. seorang pengarang yang menjadikan fenomena lingkungan dengan membandingkan Kota Bandung di Indonesia dengan Kota Paris di Perancis.Dia mengimajikan fenomena lingkungan dalam bentuk sungai. Sungai Citarum merupakan sungai yang membelah Kota Bandung sudah sangat tercemar, padahal pada tahun 1920an sungai ini merupakan ikon sungai Seine di Paris yang kita kenal pada jaman sekarang sebagai objek pariwisata yang bebas pencemaran air. Fenomena lingkungan sebenarnya berkaitan dengan budy masyarakat setempat dalam emahami dan memelihara alam. Ekofeminisme (budaya) sebagai bidang teoretis yang dilembagakan (Kaur, 2012: 101), beberapa kritikus yang telah menulis tentang Nektar dalam pandangan Saringan Rukmani berhubungan dengan tanah dan alam.

Faris Al Faisal, Faisal mengimajikan fenomena lingkungan dengan merefleksikan pohon yang dapat berbicara. Dalam pembicaraan ini pohon memiiki peran besar dalam kehidupan.Pohon dapat bertahan dari rendaman air pada musim hujan dan dapat berahan dari keeringan pada musim kemarau.Daun pohon yang berguguran menjadi petrichor atau dapat menjadi pupuk organic untuk keberlanjutan kehidupan pohon itu sendiri dan tanaman lainnya di sekitarnya.Tjak S Parlan mengimajikan fenomena lingkungan dalam bentuk bencana tanah longsor di perbkitan

AKSIS Jurnal Pendidikan Bahasa dan Sastra Indonesia

Volume 2 Nomor 2, Desember 2018 e-ISSN: 2580-9040

e-Journal: http://doi.org/10.21009/AKSIS 
akibat ulah manusia yang melakukan penambangan liar.Bukit yang dulunya hutan belantra dieksploitasi oleh penduduk di sekitarnya.Perbukitan akhirnya longsor dan menimbun para petambang yang sedang beraktivitas dan menimbulkan korban jiwa.(Trisnawati, 2014); (Mamat, 2015); (Tina, 2016); (Wiyatmi, 2016); (Junaedi, 2017); (Juanda, 2018).Penelitian ini menyoroti, polusi air, khususnya sungai, bencana alam seperti longsor dan pembalakan hutan.Fenomena tersebut yang terjadi di wilayah Indonesia yang diimajikan oleh pengarang melalui cerpen.

\section{Unsur Ekokritik Cerpen Koran Minggu Indonesia}

Berikut unsur ekokritik yang ditemukan pada setiap cerpen dengan menggunakan teori Garard (2004) yang mencakup enam persoalan lingkungan. Pengarang mengimajikan dalam bentuk cerpen mengenai persoalan pencemaran air yang menyebabkan air sungai kotor dan berbau, bencana alam seperti tanah longsor akibat penambangan liar, pentingnya merawat pohon, dan pemeliharaan hewan. Persoalan yang terjadi pada setiap cerpen berbeda-beda karena selain pengarang banyak bergelut di dunia akademik mereka juga tinggal di wilayah yang setiap tahun dilanda bencana alam. Persoalan lingkungan yang ditemukan dalam cerpen sebagai berikut:

\section{Polusi}

Pada cerpen "Di Seine Meratapi Citarum” mengisahkan tentang Rombongan turis asal Bandung yang tiba di Paris. Para wisatawan tersebut terpukau melihat keindahan wisata Kota Paris yang begitu bersih serta penduduk menjaga kelestasrian lingkungan mereka.Rombongan wisatawan tersebut teringat wisata kota asal mereka di Cikapundum dan Citarum Kota Bandung. Penulis menggunakan gaya bahasa 
personifikasi Sungai Citarum sebagai kota yang telah membangkai. Makna bangkai dalam konteks cerita diartikan sebagai sungai yang kotor, bau, air tercemar, bersampah dan banyak limbah rumah tangga. Selain itu, tatanan kota kacau balau, dan dipadati pedagang. Sekarang Sungai yang ada di kota-kota besar di Indonesia aitnya sudah berubah menjadi air got sebab para penduduk menjadkan sungai sebagai empat pembuangan sampah dan kotoran.(Trisnawati, 2014); (Mamat, 2015); (Tina, 2016); (Wiyatmi, 2016); (Junaedi, 2017).Penelitian ini menyoroti, polusi air, khususnya sungai.Fenomena tersebut yang terjadi di wilayah Indonesia yang diimajikan oleh pengarang melalui cerpen.

\section{Hutan}

Hal ini menyiratkan kepada pembaca betapa perlunya merwat tumbuhan, seakan pohon tua tersebut membutuhkan perhatian manusia agar dirawat dengan baik. Wiyatmi (Love, 2003), kajian yang menghubungkan karya sastra dengan lingkunganfisik, pertumbuhan populasi, hilangnya hutan liar dan belantara, kepunahan spesies hewan dengan cepat, serta peningkatan polusi dan kontaminasi udara, air, dan tanah di bumi.Selain itu, pohon memang memberikan manfaat bagi ekosistem karena pepohonan berfungsi menjaga keseimbangan alam. Keseimbangan alam perlu dijaga agar tidak terjadi banjir, global warming, angin ribut, dan prahara lainnya. Fenomena alam ini terdapat dalam percakapan berikut ini.Pohon memberikan banyak manfaat bagi kehidupan. Bahkan, setelah daunnya jatuh berguguran dapat bermanfaat bagi tanaman lain sebagai pupuk kompos. Persolana ini dilukiskan oleh pengarang seperti dalam kutipan berikut.Mamat (2016) bahwa prinsip nilai luhur, kecakapan dalam hidup, 
kesabaran meskipun dikekang oleh ekonomi seperti penebangan pohon, memburuh hewan, dan penggalian gunung emas.Begitu banyak manfaat yang diberikan oleh alam.Oleh karena itu, harus dikuti dengan pelestarian dan tidak mengekspolitasi.

\section{Bencana Alam}

Cerpen yang berjudul "Pergi ke Bukit" di singkat (PB).Cerita mengenai bencana tanah longsor yang terjadi bukit pertambangan emas. Para Penduduk desa maupun dari tempat lain berlomba-lomba melubangi bukit untuk mencari emas. Puisi ini mengekspresikan kerusakan alam dan kehidupan manusia yang berkaiatan budaya dan alam seperti sungai (Murugesan, 2016: 329).Interaksi manusia dengan hewan perlu dijaga.Novel Kontemporer Postkolonial yang menggambarkan pertemuan antara manusia dan hewan (Bartosch, 2013). Sementara Novel karya Ursula K.Le Guin di Vietnambertemakan malapetaka terhadap sikap antroposentris manusia terhadap alam di masa depan bilamana manusia mengeksplorasi alam secara tidak seimbang (Sureci, 2017).

\section{Pemukiman}

Pemukiman merupakan persoalan yang melanda kota-kota yang ada di Indonesia.Kota tidak memiliki ruang hijau.Seha (2016) menekankan perlunya melakukan penghijauan, dan penataan bangunan-bangunan di kota, agar memiliki resapan air yang cukup. Mishra (2017) mengkaji beberapa isu ekokritis di India yang diwakili dalam novel alam yang agung "Aranyak, Of the Forest" karya salah seorang novelis Benggali yang bernama Bandyopadhyay. Pada awal novelnya menceritakan penduduk kota dengan penebangan hutan dan sikap mereka terhadap alam. Akhir novel 
ini menimbulkan kesadaran lingkungan.Sungai-sungai yang membelah wilayah perkotaan airnya tidak layak digunakan oleh penduduk sekitrnya untuk keperluan hidup sehari-hari. Umumnya perumahan di bantaran sungai menjadikan sungai sebagi .dilakukan (Juanda, 2016) bahwa dalam memberikan pemahan pendidikan lingkungan melalui sastra anak berbasis lokal agar anak sejak dini menjaga kelestarian lingkunan di sekitarnya.

\section{Binatang}

Kehidupan binatang terganggu oleh eksploitasi alam yang dilakukan manusia. Banyak jenis burung yang telah hilang dari pandangan mata, telah punah akibat hutan telah diekploitasi oleh manusia menjadi pemukiman dan menjadi pertambangan. (Love, 2003), kajian yang menghubungkan karya sastra dengan lingkunganfisik, pertumbuhan populasi, hilangnya hutan liar dan belantara, kepunahan spesies hewan dengan cepat, serta peningkatan polusi dan kontaminasi udara, air, dan tanah di bumi. Shakespeare, melihat hubungan implisit dan eksplisit dalam teks-teks sastra antara manusia dan hewan( Estok, 2011).

\section{Bumi}

Kehidupan di permukaan bumi pada saat sekarang telah terjadi berbagai hal yang anomali.Pergantian cuaca terjadi secara tiba-tiba, kemarau yang berkepanjangan, musim hujan yang terus-menerus mengakibatkan bencana banjir, longsor.Bumi telah mengalami pemanasan global.Oleh karena itu, kesadaran dan tindakan nyata perlu dilakukan.Misalnya, di mulai hal sederhana dengan menjaga kebersihan lingkungan 
dirumah, sekolah, hingga lingkungan masyarakat.Pengarang sastra seperti WangChiahsiang, Wusheng, andWuMing-yi (Chia and Scot Slovic, 2016). Menulis Lingkungan dalam Kesusastraan Amerika Abad Kesembilan Belas dimulai dengan komentar yang mengungkap Henry David Thoreau, yang tulisan menjadi batu ujian bagi kritikus lingkungan Amerika. 'Ekspresi adalah tindakan dari seluruh manusia.Seorang penulisadalah pencipta semua alam sebagai perpaduan tubuh dan pikiran (Rudd, 2017).Flannery tampaknya menunjukkan kecenderungan dalam sastra lingkungan. 'New York Time' karya Derek Mahon,Penyair kelahiran Belfast, misalnya, menciptakan karya-karya yang menarik diri dari individualistik dan menuju mode global tempat tinggal di dunia 'truk sampah' dan 'tongkang pengungsian' dengan limbah (Gerald, 2017).

\section{KESIMPULAN}

Pengarang Romli merefleksikan fenomena lingkungan dengan membandingkan Kota Bandung di Indonesia dengan Kota Paris di Perancis dengan mengimajikan fenomena lingkungan dalam bentuk sungai. Sungai Citarum merupakan sungai yang membelah Kota Bandung sudah sangat tercemar, padahal pada tahun 1920-an sungai ini merupakan ikon sungai Seine di Paris yang kita kenal pada jaman sekarang sebagai objek pariwisata yang bebas pencemaran air. Faisal mengimajikan fenomena lingkungan dengan merefleksikan pohon yang dapat berbicara. Dalam pembicaraan ini pohon memiiki peran besar dalam kehidupan.Pohon dapat bertahan dari rendaman air pada musim hujan dan dapat berahan dari keeringan pada musim kemarau. Daun pohon yang berguguran menjadi petrichor atau dapat menjadi pupuk organic untuk 
keberlanjutan kehidupan pohon itu sendiri dan tanaman lainnya di sekitarnya. Tjak $\mathrm{S}$ Parlan mengimajikan fenomena lingkungan dalm bentuk bencana tanah longsor di perbkitan akibat ulah manusia yang melakukan penmbangan liar.Bukit yang dulunya hutan belantra dieksploitasi oleh penduduk di sekitarnya. Perbukitan akhirnya longsor dan menimbun para petambang yang sedang beraktivitas dan menimbulkan korban jiwa.

Berdasarkan kajian dalam cerpen ditemukan persoalan lingkungan yang meliputi pencemaran air, bencana alam berupa longsor di bukit tambang emas akibat eksploitasi alam yang membawa korban jiwa. Interpretasi dimulai dengan cerpen Usep Romli HM yang menceritakan persoalan pencemaran air sungai, khususnya Sungai Citarum.Cerpen karanganFaris Al Faisal dengan judul Cerita Daun, Pohon dan Petrichor menceritakan persoalan pentingnya memelihara pohon serta manfaat pohon bagi keseimbangan ekosistem. Cerpen Pergi ke Bukit menceritakan tentang tokoh ibu Kayah kehilangan anaknya akibat tertimbun tanah longsor di bukit penggalian emas. Kesadaran untuk merawat lingkungan harus dilakukan, seperti manajemen limbah dan sampah, penghijauan, pengaturan tata bangunan, dan berhenti mengeruk tambang secara berlebihan.Eksploitasi alam secara berlebihan tidak diperbolehkan. Harus ada realisasi dan sinergi secara nyata agar ekosistem terjaga.

\section{UCAPAN TERIMA KASIH}

Ucapan terima kasi penulis ucapkan kepada Lemlit Universitas Negeri Makassar yang telah mendanai penelitian ini dalam bentuk PNBP. Ucapan terima kasih kepada para pengarang cerpen yang telah mengarang cerpen yang bertemakan lingkungan sehingga memperkaya khasanah kesusastraan Indonesia khususnya genre cerpen. Kepada media Koran Mingguan Indonesia penulis mengucapkan terma kasih 
karena telah mmberikan kesempatan kepada masyarakat mengunduh cerpen malalui web lakonhidup.com.

\section{DAFTAR PUSTAKA}

Bartosch, R. (2013). Environ Mentality: Ecocriticism and the Event of Postcolonial Fiction. Amsterdam \& New York: Rodopi.

Buell, L. (1996). The Enviromental Imagination: Thoreau, Nature Writing, and the Formation of American Culture.London, England: the Belknap Press of HarvardUniversity Press, Cambridge, Masschausetts.

Chia, ju Chang \& Slovic, S. (2016). Ecocriticism in Taiwan: Identity, Environment, and the Arts. Lanham: Lexinton Books.

Dewi, N. (2015). "Manusia dan Lingkungan dalam Cerpen Indonesia Kontemporer: Analisis Ekokritik Cerpen Pilihan Kompas."Litera, Jurnal Penelitian Bahasa, Sastra, dan Pengajarannya, Vol.14 (No.2) 376-391.

Dewi, N. (2016). "Ekokritik dalam Sastra Indonesia: Kajian Sastra yang Memihak. Adabiyat, Jurnal Bahasa dan Sastra Fakultas Adab dan Ilmu Budaya, Vol. XV (1) $19-37$.

Estok, S. C. (2011). Ecocriticism and Shakespeare, Reading Ecophobia. New York: Palgrave Macmillan.

Faisal, F. A. (2018). Cerita Daun, Pohon dan Petrichor. Kompas, Tanggal 15 April 2018. Lakonhidup.

Gabriella, V. (2011). Hujan yang Indah. Kompas, Tanggal 2 April 2011. Lakonhidup com.

Garrard, G. (2004). Ecocriticism. New York: Routledge.

Gerald, L. F. (2016). Ireland And Ecocriticism: Literature, History, And Environmental Justice, by Eóin Flannery, New York and Oxen: Routledge, 278.

Glotfelty, Cheryll \& Harold Fromm.(1996). The Ecocriticism Reader: Landmark in Literary Ecology. Athens andLondon: The University of Georgia Press.

AKSIS Jurnal Pendidikan Bahasa dan Sastra Indonesia

Volume 2 Nomor 2, Desember 2018 e-ISSN: 2580-9040

e-Journal: http://doi.org/10.21009/AKSIS 
Harun, M. (2016). Fenomena lingkungan hidup dalam Puisi Anak Indonesia Usia Sekolah Dasar. Prosiding, Pendidikan Lingkungan Melalui Sastra. (Ed.) Wiyatmi, Else L., dan Dwi B. Konferensi International Kesusastraan (HISKI) XXV 13- 15 september 2016. Yogyakarta: Universitas Negeri Yogyakarta.

Hardiningtyas, P. (2016). "Masalah Tanah dan krisis Lingkungan di Bali dalam Antologi Puisi Dongeng dari Utara Karya Made Adn yana Ole.”Directory of Open Access Journals, Vol.19 (no.1) 45-59.

Harsono, S. (2008). Kritik Sastra Berwawasan Lingkungan. Jurnal Kajian Sastra, Vol.32. (No.1) 31-46.

Howarth, William. (1996). Some Principles of Ecocriticism, in Glotfelty and Fromm, 69-91.

Juanda. (2016). Pendidikan Lingkungan Peserta Didik Melalui Sastra Anak Berbasis Lokal. Prosiding, Pendidikan Lingkungan Melalui Sastra. (Ed.) Wiyatmi, Else L., dan Dwi B. Konferensi International Kesusastraan (HISKI) XXV 1315 September 2016. Yogyakarta: Universitas Negeri Yogyakarta.

Juanda, J.J. (2018). Eksplorasi Nilai Pendidikan Lingkungan Cerpen Republika: Kajian Ekokritik. Jurnal Social Humnora, 11(2), 67-81.

Love, Glen A.(2003). Practical Ecocriticism, Literatur, Biology, and the Environment. USA: University of Virginia Press.

Kaur, Gurpreet. (2012). Postcolonial Ecofeminism, Woman and Land in Kamala Markandaya's Nectar in a Sieve. International Journal of Humnities and Social Science, Vol. 2(21), 100-110.

Mishra, Sandip Kumar. (2017). "Role of Literature in Environmental Awareness: An Ecocritical Study of Aranyak (of the Forest) by Bibhutibhushan Bandyopadhyay." The Criterion: An International Journal In English. Vol.8(1), Februari 2017, pp.280-287.

Mubarok, Z. (2017). Kajian Ekokritik pada Naskah Drama Kisah Perjuangan Suku Naga Karya Rendra. Sistem Journal Online, Vol.5 (No.2) 1-24.

Murugesan, Manivannan. (2016). Emerging Environmental Conciousness in Modenr Tamil Poetry. Prosiding, Pendidikan Lingkungan Melalui Sastra (Ed.) Wiyatmi, Else L., dan Dwi B. Konferensi International Kesusastraan (HISKI) XXV 13- 15 september 2016. Yogyakarta: Universitas Negeri Yogyakarta.329-351.

Parlan, S.P. (2017). Pergi Ke Bukit. Kompas, tanggal 4 juni 2017. Lakonhidup.

AKSIS Jurnal Pendidikan Bahasa dan Sastra Indonesia

Volume 2 Nomor 2, Desember 2018 e-ISSN: 2580-9040

e-Journal: http://doi.org/10.21009/AKSIS 
Purwahida, R. (2017). Interaksi sosial pada kumpulan cerpen Potongan Cerita di Kartu Pos karangan Agus Noor dan implikasinya terhadap pembelajaran sastra di SMA. Aksis: Jurnal Pendidikan Bahasa dan Sastra Indonesia 1(1). 118-134. doi: doi.org/10.21009/AKSIS.010107

Rahmat, A. (2011). Filsafat Ilmu Lanjutan. Prenamedia Group.

Rosyidah, U.N.D. (2017). Sketsa Karya Ari Nur Utami: Arsitektur Urban dalam Perspektif Ekokritisme. Atavisme: Jurnal Ilmiah Kajian Sastra. Vol.20 (2) 205-213

Romli, U. (2017). Di Seine Meratapi. Kompas, tanggal 16 Desember 2017. Lakonhidup.

Rudd, G. (2017). Elemental ecocriticism: thinking with earth, air, water, and fire, edited by Jeffrey Jerome Cohen and Lowell Duckert, Minneapolis and London, University of Minnesota Press, Green Letters, Studies in Ecocriticism, Vol. 21(2), 215-217, DOI: 10.1080/14688417.2017.1328891.

Seha, N. (2016). Banjir Jakarta dalam Catatan Sepercik Banjir: Analisis Semiotik. Prosiding, Pendidikan Lingkungan Melalui Sastra. (Ed.) Wiyatmi, Else L., dan Dwi B. Konferensi International Kesusastraan (HISKI) XXV 13-15 september 2016. Yogyakarta: Universitas Negeri Yogyakarta.

Sureci, Y. (2017). An Ecocritical Reading Of The Word For World Is Forest.

International Journal of Social Science Number: 63, pp. 205-212.

Syahrul, N. (2016). "Kepedulian Terhadap Lingkungan Alam dan Ekologi Sebuah Ekokritik Terhadap Cerpen "Teratai Sungai Bendo" Karya M. Mahfudz Fauzi S."Prosiding, Pendidikan Lingkungan Melalui Sastra.(Ed.) Wiyatmi, Else L., dan Dwi B. Konferensi International Kesusastraan (HISKI) XXV 13-15 september 2016. Yogyakarta: Universitas Negeri Yogyakarta.

Yacoob, M., Mamat, M. (2014).Tarbiah Alam dalam Novel Komsas. Universiyi of Malaya: Akademi Pengajian Melayu, Vol.(25) 65-104.

AKSIS Jurnal Pendidikan Bahasa dan Sastra Indonesia

Volume 2 Nomor 2, Desember 2018 e-ISSN: 2580-9040

e-Journal: http://doi.org/10.21009/AKSIS 